\title{
Utility of 5-alpha-reductase inhibitors in active surveillance for favourable risk prostate cancer
}

\author{
Andrew S. Chiang, MD; ${ }^{*}$. Andrew Loblaw, MD; Vibhuti Jethava, MD;* Perakaa Sethukavalan, MD;* \\ Liying Zhang, MD; Danny Vesprini, MD; ${ }^{*}$ Alexandre Mamedov, MD, ${ }^{\ddagger}$ Robert Nam, MD, FRCSC,* \\ Laurence Klotz, MD, FRCSC
}

\begin{abstract}
*Department of Radiation Oncology, Sunnybrook Health Sciences Centre, University of Toronto, Toronto, ON; 'Department of Biostatistics, Sunnybrook Health Sciences Centre, University of Toronto, Toronto, ON; §Department of Clinical Trials and Epidemiology, Sunnybrook Health Sciences Centre, University of Toronto, Toronto, ON; *Division of Urology, Sunnybrook Health Sciences Centre, University of Toronto, Toronto, ON
\end{abstract}

See related article on page 454 .

Cite as: Can Urol Assoc J 2013;7(11-12):450-3. http://dx.doi.org/10.5489/cuaj.262 Published online December 5, 2013.

\section{Abstract}

Introduction: This retrospective review compares prostate-specific antigen (PSA) doubling time (DT) prior to the initiation of a 5-alphareductase inhibitor (pre-5-ARI) to after the PSA nadir (post-nadir) has been reached for patients on active surveillance for favourablerisk prostate cancer.

Methods: Between 1996 and 2010, a total of 100 men with a history of 5-ARI use were captured from our active surveillance database. Twenty-nine patients had a sufficient number of PSA values to determine both pre-5-ARI and post-nadir DTs. PSADT was calculated using the general linear mixed-model method.

Results: The median follow-up was 69.5 months. The median pre-5-ARI PSADT was 55.8 (range: 6-556.8) months, while the post-nadir value was 25.2 (range: $6-231)$ months $(p=0.0081)$. Six patients were reclassified after an average of 67.7 (range: 59-95) months, due to progression in PSADT $(n=2)$ or Gleason score $(n=4)$. The median pre-5-ARI and post-nadir DTs for this group were 42.3 (range: $32.4-91.1$ ) and 21.1 (range: 6-44.3) months, respectively.

Conclusion: 5-ARIs significantly decreased PSADT compared to prior to their initiation. This effect may be due to preferential suppression of benign tissue following PSA nadir. The resulting PSADT would then represent a more accurate depiction of the true cancerrelated DT. If validated with a larger cohort, 5-ARIs may enhance the utility of PSADT as a biomarker of disease progression in active surveillance.

\section{Introduction}

Prostate cancer is common in North America. ${ }^{1,2}$ Over the past 2 decades, there have been increasingly more favour- able-risk cases due to prostate-specific antigen (PSA) screening. ${ }^{3}$ More and more patients are now choosing active surveillance as their primary management option. This allows men to potentially avoid overtreatment, while still being able to have curative therapy if reclassified to higher risk disease. About $7 \%$ to $23 \%$ of patients are now initially managed with some form of a conservative approach..$^{3-5}$

By avoiding radical treatment upfront, there is a growing interest in determining whether 5- alpha-reductase inhibitors (5-ARIs) can potentially delay disease progression in active surveillance. These drugs act by inhibiting the conversion of testosterone to the more active dihydroxytesterone. The result is a decrease in the proliferation of both benign and malignant prostatic tissue. ${ }^{6}$ 5-ARIs have already been quite heavily studied in the preventive setting, but their role in patients already diagnosed with prostate cancer is still under investigation. ${ }^{7,8}$

One of the few randomized studies that evaluated 5-ARIs in active surveillance patients is the REDEEM (Reduction by Dutasteride of Clinical Progression Events in Expectant Management) trial. ${ }^{9}$ A total of 304 favourable-risk patients were randomized to either dutasteride or placebo for 3 years. The intervention arm significantly reduced the risk of disease progression (38\% vs. $49 \%, p=0.009$ ), which was defined as the initiation of therapy or pathological progression. Investigators also reported no increase in the number of high-grade cases and no difference in adverse events. However, the impact of 5-ARIs on PSA kinetics remains unclear.

Previous studies show that 5-ARIs cause a decrease in PSA levels by about $50 \%$ within 3 to 6 months. ${ }^{10}$ The duration of response is variable and patients will inevitably experience a PSA rise. The subsequent effect on PSA doubling time (DT), which represents a key parameter in many surveillance strategies, is currently unknown. In this retrospective review, we compare PSADT before initiating a 5-ARI to PSADT after the nadir has been reached. 


\section{Methods}

Between 1996 and 2010, there were 100 patients who had used a 5-ARI at some point in their management; this was captured from our active surveillance database with over 800 men. Baseline tumour characteristics and additional 5-ARI information, including start and end date, were acquired using medical records or by contacting patients directly. Surveillance and, if applicable, treatment courses were also documented in this manner. Approval of this study was obtained from the Sunnybrook Health Sciences Centre Research Ethics Board.

PSADT was calculated both prior to the initiation of a 5-ARI (pre-5-ARI) and after the PSA nadir (post-nadir). At least 3 PSA values were required for each and the calculation was done using the general linear mixed-model method. ${ }^{11}$ In total, 27 patients had a sufficient number of PSA values. Exceptions were then made in 2 additional cases as both patients underwent surgery after only 2 consecutive PSA rises. Grade progression was confirmed on repeat biopsy prior to surgery.

Patients were assessed every 3 to 6 months with biopsies at 12 months following initial diagnosis and then every 3 to 4 years thereafter. Reclassification was defined as per our institutional protocol (i.e., PSADT $\leq 3$ years, histologic upgrade, and/or unequivocal clinical progression). ${ }^{12}$ For postprostatectomy patients, biochemical failure was defined as a serum PSA level $\geq 0.2 \mu \mathrm{g} / \mathrm{L} .{ }^{13}$ For post-radiotherapy patients, there had to be a PSA rise of at least $2 \mu \mathrm{g} / \mathrm{L}$ above nadir. ${ }^{14}$

\section{Statistical analysis}

Results are expressed as median and range (minimum to maximum) for continuous variables, while proportions are used for categorical variables. Statistical analysis was performed using the non-parametric sign test to compare the 2 sets of doubling times. All analyses were conducted by Statistical Analysis Software (SAS version 9.2 for Windows) and PROC Univariate procedure was applied for comparison. A $p$ value $<0.05$ was considered statistically significant.

\begin{tabular}{lcc}
\hline \multicolumn{3}{l}{ Table 1. T stage and Gleason score at time of presentation } \\
\hline T stage & No. $(\mathbf{n}=\mathbf{2 9})$ & Percentage \\
\hline T1b & 1 & $3.4 \%$ \\
T1c & 26 & $89.8 \%$ \\
T2a & 1 & $3.4 \%$ \\
Unknown & 1 & $3.4 \%$ \\
Gleason score & No. (n=29) & Percentage \\
5 & 2 & $6.9 \%$ \\
6 & 25 & $86.3 \%$ \\
7 & 1 & $3.4 \%$ \\
Unknown & 1 & $3.4 \%$ \\
\hline
\end{tabular}

\section{Results}

In this cohort of 29 patients, most had stage T1c disease $(89.8 \%)$ and Gleason scores of 6 or lower (93.2\%) (Table 1). The average PSA at presentation was $6.93(1.08-15.6 \mu \mathrm{g} / \mathrm{L})$. Twenty-five of these men (86.2\%) would be considered lowrisk prostate cancer as per the National Comprehensive Cancer Network criteria. ${ }^{15}$ In terms of the 5-ARI, more patients were prescribed dutasteride $(79.3 \%)$ than finasteride $(20.7 \%)$.

Median follow-up was 69.5 (range: $32-154$ ) months. The median pre-5-ARI PSADT was 55.8 (range: 6-557) months, while that for the post-nadir values was 25.2 (range: 6-231) months $(p=0.0081)$. The PSA values used to calculate these results were, on average, 8.79 (range: 1.08-27.37) and 6.52 (range: $0.81-25.1) \mu \mathrm{g} / \mathrm{L}$, respectively. Six patients were reclassified after an average of 67.7 (range: 59-95) months, due to progression in PSADT $(n=2)$ or Gleason score $(n=4)$ (Table 2). The median pre-5-ARI and post-nadir DTs for this group were 42.3 (range: 32.4-91.1) and 21.2 (range: 6-44.3) months, respectively.

Of the 6 reclassified patients, 5 subsequently underwent radical prostatectomy, while 1 underwent radical radiotherapy with androgen deprivation. Only 1 had biochemical failure after a median post-treatment follow-up period of 10 (range: 0-52) months. This particular patient had a detectable postoperative PSA and was immediately started on androgen deprivation. He has had biochemical control for 24 months at last follow-up.

\section{Discussion}

Active surveillance is one of the recommended management options for favourable-risk prostate cancer. ${ }^{15}$ The premise is that the long natural history of early stage disease will be outpaced by death from other causes. Definitive treatment is reserved for patients who are reclassified to higher

\begin{tabular}{|c|c|c|c|c|}
\hline Case & $\begin{array}{c}\text { Time to } \\
\text { reclassification }\end{array}$ & Reason & Treatment & Outcome \\
\hline 1 & 68 months & PSA & Surgery & $\begin{array}{c}\text { Biochemical } \\
\text { control }\end{array}$ \\
\hline 2 & 64 months & $\begin{array}{c}\text { Gleason } \\
\text { score }\end{array}$ & Surgery & $\begin{array}{l}\text { Biochemical } \\
\text { progression }\end{array}$ \\
\hline 3 & 60 months & $\begin{array}{c}\text { Gleason } \\
\text { score }\end{array}$ & Surgery & $\begin{array}{l}\text { Biochemical } \\
\text { control }\end{array}$ \\
\hline 4 & 95 months & PSA & Surgery & $\begin{array}{l}\text { Biochemical } \\
\text { control }\end{array}$ \\
\hline 5 & 59 months & $\begin{array}{c}\text { Gleason } \\
\text { score }\end{array}$ & Surgery & $\begin{array}{l}\text { Biochemical } \\
\text { control }\end{array}$ \\
\hline 6 & 60 months & $\begin{array}{c}\text { Gleason } \\
\text { score }\end{array}$ & $\begin{array}{c}\text { Radiation and } \\
\text { hormones }\end{array}$ & $\begin{array}{c}\text { Biochemical } \\
\text { control }\end{array}$ \\
\hline
\end{tabular}


Chiang et al.

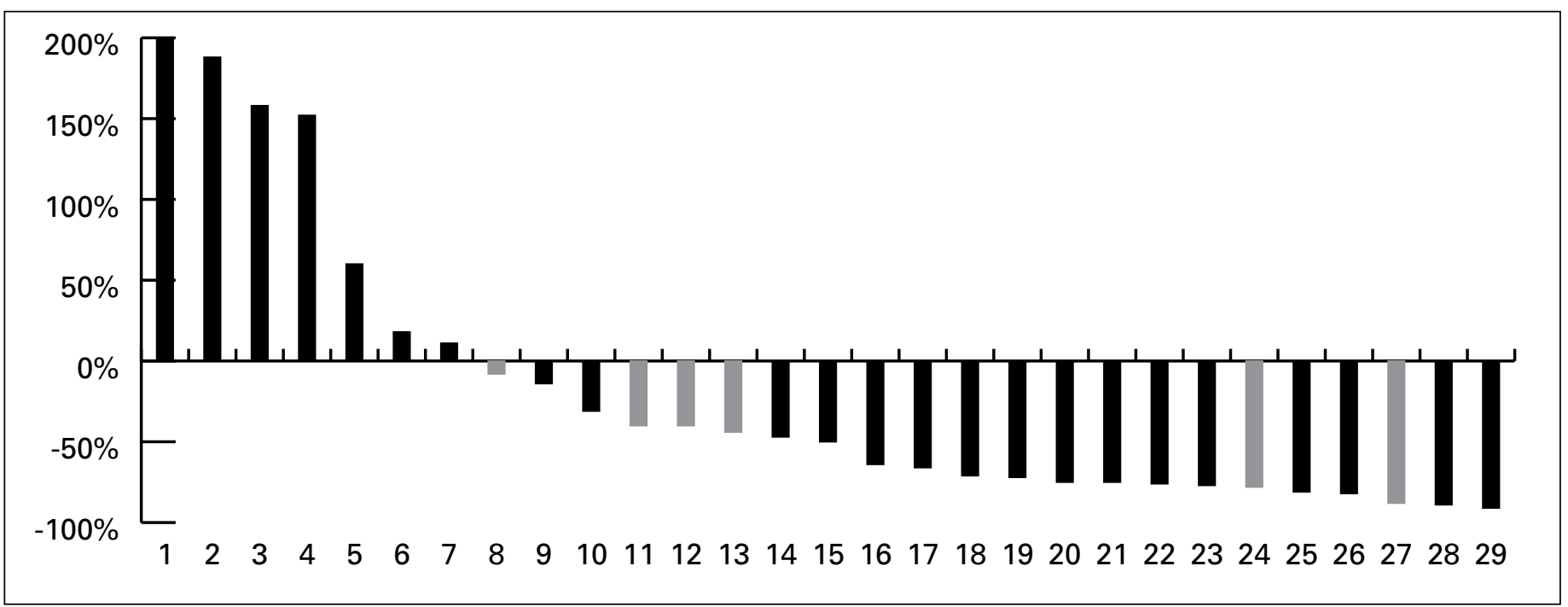

Fig. 1. Percent change of the post-nadir doubling time relative to the corresponding pre-5- alpha-reductase inhibitor value for each individual patient in ordinal order. Note: The percent change for patient 1 is $1844 \%$, but was truncated at $200 \%$ for formatting purposes. Reclassified patients ( $\mathrm{n}=6$ ) are highlighted in grey.

risk disease. Regardless of outcome, the cause-specific survival in this group is still very high $(95 \%-100 \%) .{ }^{16}$ The role of 5-ARIs in this setting has not been particularly wellestablished. This retrospective review looked specifically at its influence on PSADT, a commonly used biomarker for disease progression. ${ }^{17}$

There is currently a lack of standardization when it comes to calculating PSADT and the inclusion criteria for its PSA values. Our preference has been to use the general linear mixed model method proposed by Zhang and colleagues, which was predicated on a large active surveillance cohort. ${ }^{11}$ The requirement of at least 3 PSA values (not necessarily consecutively rising) is consistent with a previously reported working group guideline. ${ }^{18}$ It likely represents the best tradeoff in terms of maintaining a sufficient sample size and not being overly influenced by the inherent variability of PSA. Though not mandatory, values were obtained at least 4 weeks apart and over a period of at least 3 months to again deal with this variation issue.

Our primary finding was that the median post-nadir PSADT was significantly faster relative to the median pre-5ARI value. As PSA suppression is sustained in non-malignant tissue, these results are intriguing with mounting clinical evidence that 5-ARIs do not cause disease progression. This finding may actually represent preferential cytoreduction of benign prostatic tissue that occurs around the time of PSA nadir. The resulting PSADT would then be a more accurate depiction of the true cancer-related DT. This change has obvious implications in terms of surveillance strategies and even reclassification criteria.

Another advantage of 5-ARIs is that they may identify the subset of patients that have higher risk prostate cancer from the onset. Previous data have shown an increased detection rate of higher grade disease (Gleason score 7-10) for 5-ARI patients with a rising PSA compared to those with stable values and those not on 5 -ARIs. ${ }^{19}$ It is these men that would most likely benefit from earlier therapeutic intervention. This approach is further supported by evidence that active surveillance patients have a relatively higher likelihood of biochemical failure compared to those that are treated upfront. ${ }^{12}$ Therefore, by identifying aggressive disease early on, we can offer these patients a greater chance of cure.

For this group, only $20.6 \%(6 / 29)$ of patients were reclassified, which is less than our general cohort (about 30\%). ${ }^{12}$ The absolute benefit between these 2 groups seems consistent with results from the REDEEM trial. ${ }^{9}$ However, drawing any conclusions based on these results are limited by the retrospective nature of this study and its limited sample size. The latter can be attributed primarily to the large number of patients excluded due to insufficient PSA values. In most cases, the reason was that the patient was not on the medication long enough for a post-nadir DT to be calculated. This data support the belief that 5-ARIs lower the rate of disease progression in active surveillance.

In terms of reclassification, most of our patients were treated based on grade progression $(67 \% ; 4 / 6)$. This is in contrast to our institutional cohort, where more men were reclassified and then treated due to a change in PSADT (48\% vs. $27 \%$ for grade progression). ${ }^{12}$ Again, these results are limited, but 5-ARIs might be able to reduce the proportion of cases treated just on PSA kinetics alone. The issue with this approach is the inherent risk of overtreatment by basing reclassification on non-histological criteria. By virtue of this shift, our reclassification rates would serve as a better reflection of true disease upgrading.

Based on the PCPT and REDUCE studies, one of the 
concerns with using 5-ARIs is the increased risk of highgrade tumours. ${ }^{6,7}$ With logistic regression analyses, this difference is not significant when prostate volume is taken into account. ${ }^{20,21}$ The smaller gland sizes due to 5-ARI use may have resulted in disproportionate sampling at biopsy. These results are similar to the Combination of Avodart (GlaxoSmithKline Inc.) and Tamsulosin (CombAT) study in which there was a reduction in prostate cancer across all Gleason scores. ${ }^{22}$ For patients with known prostate cancer, the REDEEM trial showed no increase in the number of high-grade cases. ${ }^{9}$ Thus, based on more recent data, it seems increasingly unlikely that 5-ARIs cause grade progression.

\section{Conclusion}

In the setting of active surveillance, 5-ARIs significantly decreased post-nadir DT compared to the corresponding pre-5-ARI value. This finding may be related to the preferential suppression of benign prostatic tissue. Therefore, the post-nadir DT would represent a more accurate reflection of the true malignancy-related DT. If validated with a larger cohort, 5-ARIs may enhance the importance of PSADT as a biochemical surrogate for disease progression in active surveillance.

Competing interests: Dr. Loblaw has consulted with, and has received honorarium from GE Healthcare. Dr. Chiang, Dr. Jethava, Dr. Sethukavalan, Dr. Zhang, Dr. Vesprini, Dr. Mamedov, Dr. Nam and Dr. Klotz all declare no competing financial or personal interests.

This paper has been peer-reviewed.

\section{References}

1. Canadian Cancer Society. Canadian Cancer Statistics, 2011. http://www.cancer.ca/en/about-us/for$\mathrm{media} / \mathrm{media}-\mathrm{releases} /$ new-brunswick/2011/canadian-cancer-statistics-2011/? region=nb. Accessed November 13, 2013.

2. American Cancer Society. Cancer Facts \& Figures 2011. Atlanta: American Cancer Society; 2011. http://www.cancer.org/acs/groups/content/@epidemiologysurveilance/documents/document/ acspc-029771.pdf. Accessed November 13, 2013.

3. Cooperberg MR, Broering JM, Kantoff PW, et al. Contemporary trends in low risk prostate cancer: risk assessment and treatment. J Urol 2007;178:S14-9. http://dx.doi.org/10.1016/i.juro.2007.03.135

4. Shappley III WV, Kenfield SA, Kasperzyk JL, et al. Prospective study of determinants and outcomes of deferred treatment or watchful waiting among men with prostate cancer in a nationwide cohort. J Clin Oncol 2009;27:4980-5. http://dx.doi.org/10.1200/JC0.2008.21.2613

5. Welch HG, Albertsen PC. Prostate cancer diagnosis and treatment after the introduction of prostate-specific antigen screening: 1986-2005. J Natl Cancer Inst 2009;101:1325-9. http://dx.doi.org/10.1093/ inci/dip278
6. Iczkowski KA, Qiu J, Somerville MC, et al. Dual 5-alpha-reductase inhibitor dutasteride induces atrophic changes and decreases relative cancer volume in human prostate. Urology 2005;65:76-82. http:// dx.doi.org/10.1016/j.urology.2004.08.042

7. Thompson IM, Goodman PJ, Tangen CM, et al. The influence of finasteride on the development of prostate cancer. N Engl J Med 2003;349:215-24. http://dx.doi.org/10.1056/NEJMoa030660

8. Andriole GL, Bostwick DG, Brawley OW, et al. Effect of dutasteride on the risk of prostate cancer. $N$ Engl J Med 2010;362:1192-202. http://dx.doi.org/10.1056/NEJMoa0908127

9. Fleshner NE, Lucia MS, Egerdie B, et al. Dutasteride in localised prostate cancer management: the REDEEM randomised, double-blind, placebo-controlled trial. Lancet 2012;379:1103-11. http://dx.doi. org/10.1016/S0140-6736(11)61619-X

10. Gormley GJ, Stoner E, Bruskewitz RC, et al. The effect of finasteride in men with benign prostatic hyperplasia. The Finasteride Study Group. N Engl J Med 1992;327:1185-91. http://dx.doi.org/10.1056/ NEJM199210223271701

11. Zhang L, Loblaw A, Klotz L, et al. Modelling prostate specific antigen kinetics in patients on active surveillance. J Urol 2006;176:1392-7; discussion 1397-8. http://dx.doi.org/10.1016/i.juro.2006.06.103

12. Klotz L, Zhang L, Lam A, et al. Clinical results of long-term follow-up of a large, active surveillance cohort with localized prostate cancer. J Clin Oncol 2010;28:126-31. http://dx.doi.org/10.1200/ JC0.2009.24.2180

13. Cookson MS, Aus G, Burnett AL, et al. Variation in the definition of biochemical recurrence in patients treated for localized prostate cancer: the American Urological Association Prostate Guidelines for Localized Prostate Cancer Update Panel report and recommendations for a standard in the reporting of surgical outcomes. J Urol 2007;177:540-5. http://dx.doi.org/10.1016/i.juro.2006.10.097

14. Roach III $M$, Hanks $G$, Thames Jr $H \mathrm{Jr}$, et al. Defining biochemical failure following radiotherapy with or without hormonal therapy in men with clinically localized prostate cancer: recommendations of the RTOG-ASTRO Phoenix Consensus Conference. Int J Radiat Oncol Biol Phys 2006;65:965-74. http:// dx.doi.org/10.1016/i.i.jiobp.2006.04.029

15. Mohler J, Bahnson RR, Boston B, et al. NCCN clinical practice guidelines in oncology: prostate cancer. J Natl Compr Canc Netw 2010;8:162-200.

16. Stattin P, Holmberg E, Johansson JE, et al. Outcomes in localized prostate cancer: National Prostate Cancer Register of Sweden follow-up study. J Natl Cancer Inst 2010;102:950-8. http://dx.doi.org/10.1093/ inci/diq154

17. McLaren DB, McKenzie M, Duncan G, et al. Watchful waiting or watchful progression?: Prostate specific antigen doubling times and clinical behavior in patients with early untreated prostate carcinoma. Cancer 1998;82:342-8. http://dx.doi.org/10.1002/(SICI) 1097-0142(19980115)82:2<349::AIDCNCR15>3.0.C0;2-2

18. Arlen PM, Bianco F, Dahut WL, et al. Prostate Specific Antigen Working Group guidelines on prostate specific antigen doubling time. J Urol 2008;179:2181-5; discussion 2185-6. http://dx.doi.org/10.1016/i. juro.2008.01.099

19. van Leeuwen PJ, Kölble K, Huland $\mathrm{H}$, et al. Prostate cancer detection and dutasteride: utility and limitations of prostate-specific antigen in men with previous negative biopsies. Eur Urol 2011;59:183-90. http:// dx.doi.org/10.1016/i.eururo.2010.09.035

20. Cohen YC, Liu KS, Heyden NL, et al. Detection bias due to the effect of finasteride on prostate volume: a modeling approach for analysis of the Prostate Cancer Prevention Trial. J Natl Cancer Inst 2007;99:136674. http://dx.doi.org/10.1093/inci/diml30

21. Lucia MS, Epstein Jl, Goodman PJ, et al. Finasteride and high-grade prostate cancer in the Prostate Cancer Prevention Trial. J Natl Cancer Inst 2007;99:1375-83. http://dx.doi.org/10.1093/inci/diml17

22. Roehrborn CG, Andriole GL, Wilson TH, et al. Effect of dutasteride on prostate biopsy rates and the diagnosis of prostate cancer in men with lower urinary tract symptoms and enlarged prostates in the Combination of Avodart and Tamsulosin trial. Eur Urol 2011;59:244-9. http://dx.doi.org/10.1016/j. eururo.2010.10.040

Correspondence: Dr. Andrew Loblaw, 2075 Bayview Ave., Rm T2-103, Toronto, ON M4N 3M5; fax: 416-480-6002; andrew.loblaw@sunnybrook.ca 